\title{
Subgrid parameterization of snow distribution at a Mediterranean site using terrestrial photography
}

\author{
Rafael Pimentel $^{1,2}$, Javier Herrero ${ }^{3}$, and María José Polo ${ }^{1}$ \\ ${ }^{1}$ Fluvial Dynamics and Hydrology Research Group, Andalusian Institute for Earth System Research, \\ University of Córdoba, Campus Rabanales, Edificio Leonardo da Vinci, Área de Ingeniería Hidráulica, \\ 14017, Córdoba, Spain \\ ${ }^{2}$ Hydrology Research, Swedish Meteorological and Hydrological Institute, Folkborgsvägen, 17, \\ 60176 , Norrköping, Sweden \\ ${ }^{3}$ Fluvial Dynamics and Hydrology Research Group, Andalusian Institute for Earth System Research, \\ University of Granada, Edificio CEAMA, Avenida del Mediterráneo s/n, 18006, Granada, Spain \\ Correspondence to: Rafael Pimentel (rafael.pimentel@ smhi.se)
}

Received: 19 August 2016 - Discussion started: 19 September 2016

Accepted: 14 January 2017 - Published: 10 February 2017

\begin{abstract}
Subgrid variability introduces non-negligible scale effects on the grid-based representation of snow. This heterogeneity is even more evident in semiarid regions, where the high variability of the climate produces various accumulation melting cycles throughout the year and a large spatial heterogeneity of the snow cover. This variability in a watershed can often be represented by snow accumulation-depletion curves (ADCs). In this study, terrestrial photography (TP) of a cell-sized area $(30 \times 30 \mathrm{~m})$ was used to define local snow ADCs at a Mediterranean site. Snow-cover fraction (SCF) and snow-depth $(h)$ values obtained with this technique constituted the two datasets used to define ADCs. A flexible sigmoid function was selected to parameterize snow behaviour on this subgrid scale. It was then fitted to meet five different snow patterns in the control area: one for the accumulation phase and four for the melting phase in a cycle within the snow season. Each pattern was successfully associated with the snow conditions and previous evolution. The resulting ADCs were associated to certain physical features of the snow, which were used to incorporate them in the point snow model formulated by Herrero et al. (2009) by means of a decision tree. The final performance of this model was tested against field observations recorded over four hydrological years (2009-2013). The calibration and validation of this ADC snow model was found to have a high level of accuracy, with global RMSE values of $105.8 \mathrm{~mm}$ for the average snow depth and $0.21 \mathrm{~m}^{2} \mathrm{~m}^{-2}$ for the snow-cover fraction in
\end{abstract}

the control area. The use of ADCs on the cell scale proposed in this research provided a sound basis for the extension of point snow models to larger areas by means of a gridded distributed calculation.

\section{Introduction}

Subgrid variability plays a crucial role in grid-based distributed hydrological modelling. The scale issue introduced when a point model is applied to a gridded area conditions the accuracy of the processes represented (Blöschl, 1999). This is especially important in physical modelling because of the non-linearity usually found in natural systems, which does not allow the assumption of homogeneity within each grid cell.

This is the case of snow models based on energy and water balance (Anderson, 1976; Herrero et al., 2009; Tarboton and Luce, 1996; Wigmosta et al., 1994). The spatial distribution of snow can be very heterogeneous. In cold northern regions, wind-drifting, canopy interception, and micro-relief make the distribution of snow rather discontinuous (Sturm and Holmgren, 1994). Moreover, in warm mid- and low-latitude locations, such as the mountainous areas in Mediterraneantype regions, the changeable climate conditions make the allocation of the snow even more variable and irregular. There may be several accumulation-melting cycles throughout the 
year, and a wide range of snow-depth states can occur even within small areas. Micro-topography plays an important role in this high spatiotemporal variability, being the characteristic snow-depth values usually of the same order of magnitude than this micro-relief $(0-1000 \mathrm{~mm})$, and this effect, despite complexities, should be included in gridded representations (Anderton et al., 2004).

Accumulation-snowmelt models tackle this problem from different approaches. Wigmosta et al. (1994) include the effects of local topography and vegetation cover in physical snow modelling in the distributed hydrology soil vegetation model (DHSVM). In contrast, the cold regions hydrological model (CRHM) (Pomeroy et al., 2007), which includes a full range of modules that represent hydrological processes in cold regions, employs a single conception of cascading hydrological response units (HRU). Neither of these models, however, consider the effects of the interaction between micro-topography and snow. This could be a constraint for their application on smaller scales.

Isnobal (Marks and Dozier, 1992) introduces the effect of topography interaction on snow-wind redistribution by determining the formation of drifts and scour zones at the element scale. However, it does not address the effect of low relief on the cell size. Luce et al. (1999) take a physically based snow model and enrich it with the concept of the depletion curve (DC), previously used in runoff prediction based on temperature-index-based melting estimates (Buttle and McDonnel, 1987; Ferguson, 1984). They use DCs for parameterizing subgrid variability in a physical model, which considered the study area as a single model element to reduce the area involved in mass and energy balance as snow regression progresses. These DCs relate a snow-state variable, such as snow water equivalent (SWE) or snow depth $(h)$, to the snow-cover fraction (SCF) in a selected area. Following this approach, Luce and Tarboton (2004) define a DC in a watershed based on in situ SWE measurements. In addition, Kolberg et al. (2006) used remote sensing information and a Bayesian approach to parameterize a DC on watershed scale. These results show the applicability of this approach to reproduce snow regression in medium- to large-sized areas.

Nevertheless, the heterogeneous spatial and temporal snow distribution in semiarid environments makes it difficult to define a single DC for a whole watershed because the evolution of the different snow accumulation-melting cycles that usually occur during the snow season in these regions can differ considerably (Pimentel et al., 2015). A distributed application of DCs could be used to capture this variability, and thus provide a better representation of the physical processes underlying the evolution of snow cover and snow quantity in a given area. This is the approach that was followed in this research study.

A general sigmoid shape is representative of these cycles:
1. an asymptotic trend at the end (beginning) of the accumulation (melting) processes, when most of the cell area is covered by snow;

2. a increasing (decreasing) trend, corresponding to the period in which snow is falling (melting) in the accumulation-melting processes; and

3. a final phase, in which the accumulation (melting) begins (finishes) and small isolated areas can be found with snow patches.

The basic snow variable needed to define a DC is the snowcover fraction over the area to be scaled. Remote sensing is the most common and powerful extended source to obtain this information in medium- and large-sized areas. However, to represent the snow distribution at subgrid scales, higher temporal and spatial resolutions may be required. Terrestrial photography (TP) of a snow-covered scene is an efficient alternative because its temporal and spatial resolution can be adapted to the scale of the processes driving the snow evolution (Corripio, 2004; Farinotti et al., 2010; Pérez-Palazón et al., 2014; Pimentel et al., 2012, 2015; Rivera et al., 2008). Moreover, TP at this scale also provides snow-depth measurements at selected points within the images. This is accomplished by means of coloured poles located in the area that can be clearly identified and differentiated from the rest of the image.

This study used an innovative approach for incorporating the effects of the spatial variability of the snow distribution at the subgrid scale into snow modelling by means of TP, based on previous work (Pimentel et al., 2015). For this purpose, a 4-year series of TP images of a $30 \times 30 \mathrm{~m}$ scene at a snow monitoring site in the Sierra Nevada (southern Spain) was used to derive DC parameterizations representative of different snow accumulation-melting cycles. The resulting DCs were included in the snow model developed by Herrero et al. (2009) and Herrero and Polo (2012), and the performance of this DC model was finally tested against field observations.

\section{Study site and available data}

This study was carried out in Sierra Nevada, southern Spain $\left(37^{\circ} \mathrm{N}\right.$ latitude), where the highest altitudes in the Iberian Peninsula can be found ( $3479 \mathrm{~m}$ a.s.l.). Sierra Nevada is a linear mountain range, which run $90 \mathrm{~km}$ parallel to the Mediterranean coast. The interaction between the semiarid Mediterranean climate and the alpine conditions in this area results in a highly variable snow regime. The snow usually appears above $2000 \mathrm{~m}$ a.s.l. during winter and spring even though the snowmelt season generally lasts from April to June. The typically mild Mediterranean winters produce several snowmelt cycles before the final melting phase, which distributes the snow in patches over the terrain. Precipitation is heteroge- 
neously distributed over the area because of the steep orography, with a high annual variability $(400-1500 \mathrm{~mm})$. The average temperature during the snow season can range from -5 to $5{ }^{\circ} \mathrm{C}$, reaching values as low as $-20^{\circ} \mathrm{C}$ at certain times in the winter (Pérez-Palazón et al., 2015).

A control area of $900 \mathrm{~m}^{2}$ was selected and sized, according to a grid-cell area of $30 \times 30 \mathrm{~m}$. This cell size corresponds to the resolution of Landsat TM scenes, which are used to monitor snow extension over long time periods. This area is located near the weather monitoring station, Refugio Poqueira (Fig. 1), at $2500 \mathrm{~m}$ a.s.l. This plot is composed of rocks as well as of compact, low, densely branched shrubs, mainly Genista versicolor and Festuca indigesta, which act as insulators between the soil and the snowpack. They constitute the main representative elements of the low relief of Sierra Nevada above $2000 \mathrm{~m}$ a.s.l., where there are only isolated patches of reforested pine trees.

The weather station has been operating since 2004. It generates 5-minute data records pertaining to precipitation, solar radiation, long-wave radiation, wind velocity, temperature, air humidity, and atmospheric pressure. In the summer of 2009, an automatic CC640 Campbell Scientific camera was also installed and programmed to obtain 5 images per day, every $2 \mathrm{~h}$ between 08:00 and 16:00 LT, of the control area with a resolution of $640 \times 504$ pixels. This camera is able to capture both the rapid snow melting cycles and the spatial heterogeneity exhibited by the snow cover at the study site in relation to its micro-topography. Additionally, two snow measuring poles were installed in the photographed area to measure snow depth. Thus, the TP was able to monitor SCF and a representative snowpack depth $\left(h_{\text {ref }}\right)$ at the study site with a high recording frequency. The SCF and $h_{\text {ref }}$ series in Pimentel et al. (2015), which extend up to the summer of 2013, were used in this work. Tables 1 and 2 show representative climate and snow variables in the control area during the study period.

A digital elevation model (DEM) with a resolution of $0.05 \times 0.05 \mathrm{~m}$ was derived from topographic surveys of the control area. This DEM was used to project the TP images and analyse their information.

\section{Methods}

Four consecutive hydrological years (2009-2013) were analysed at the study site. The DCs at subgrid scale were derived from the SCF and average snow-depth $(\bar{h})$ values obtained from the TP images during the study period, and were parameterized by means of flexible sigmoid functions. These DCs were incorporated into the point model of the study site, elaborated by Herrero et al. (2009). This section describes the steps in this process: (i) the definition of DCs, (ii) the way that SCF and $h$ values were obtained from TP, (iii) the point snowmelt-accumulation model, and (iv) the inclusion of DCs in the model.

\subsection{Accumulation-depletion curves (ADCs)}

The $\bar{h}$ over the control area and the SCF values were selected to express the curves representative of accumulatingmelting cycles. Each cycle corresponds to the time period between the beginning of a snowfall event and the end of the complete ablation of the snow or the occurrence of a new snowfall event. Each cycle thus has two consecutive phases, accumulation and melting, and for this reason, a different curve was obtained for each phase in every cycle during the study period. In the accumulation-depletion curve (ADC) definition, dimensionless $\bar{h}\left(\bar{h}^{*}=\bar{h} / \bar{h}_{\max }[x\right.$ axis $\left.]\right)$ and SCF $\left(\mathrm{SCF}^{*}=\mathrm{SCF} / \mathrm{SCF}_{\max }[y\right.$ axis $\left.]\right)$ values scaled based on the maximum average snow depth $\left(\bar{h}_{\text {max }}\right)$ and the maximum SCF $\left(\mathrm{SCF}_{\max }\right)$, of each cycle respectively, were used to minimize the variability throughout the cycles in the study period. Both variables were obtained from the TP series recorded at the study area (see Sect. 3.2). The flexible sigmoid function given by Eq. (1) was used as the ADC parameterization. This function, which was adapted from that proposed by Yin et al. (2003) to characterize crop growth, provides a flexible description of asymmetrical sigmoid patterns, numerical stability of parameters in statistical estimation, prediction of a zero value at the origin of the coordinates, and easy truncation to represent asymptotic behaviour.

$$
\operatorname{SCF}_{i}^{*}=\left\{\begin{array}{cc}
\operatorname{SCF}_{i_{\max }}^{*}\left(1+\frac{\bar{h}_{i_{e}}^{*}-\bar{h}_{i}^{*}}{\bar{h}_{i_{e}}^{*}-\bar{h}_{i_{m}}^{*}}\right)\left(\frac{\bar{h}_{i}^{*}}{\bar{h}_{i_{e}}^{*}}\right)^{\frac{\bar{h}_{i_{e}}^{*}}{\bar{h}_{i_{e}}^{*} \bar{h}_{i m}^{*}}} & \text { if } 0 \leq \bar{h}_{i}^{*}<\bar{h}_{i_{e}}^{*} \\
& \text { if } \bar{h}_{i}^{*} \geq \bar{h}_{i_{e}}^{*}
\end{array}\right.
$$

This function has three parameters, $\mathrm{SCF}_{i_{\max }}^{*}, \bar{h}_{i_{e}}^{*}$, and $\bar{h}_{i_{m}}^{*}$, which are, respectively, the maximum value of $\mathrm{SCF}^{*}$ for a given cycle, the dimensionless snow depth when the melting begins, and the dimensionless snow depth when the maximum melt rate is reached during a cycle. The sub-index $i$ represents each of the cycles during the study period.

The time evolution of the SCF during the study period was analysed to define the set of accumulation-melting cycles. The accumulation phase exhibited low variability whereas the melting phase of the cycles showed considerable variation. Consequently, a single sigmoid function fits all the accumulation phases in the selected cycles, whereas different curves were fitted for each snowmelt phase. The fitting procedure was iterative to cluster the ADCs after cycles with a similar regime. ADCs with close fitted values $(10 \%$ difference) were clustered, and then a second fit was performed for the whole dataset, and so on.

\subsection{Terrestrial photography analysis: SCF and snow-depth measurements}

The SCF and $\bar{h}$ series used in this work were obtained by following the methodology proposed by Pimentel et al. (2012, 2015) and Pérez-Palazón et al. (2014), which consists of a two-step method involving georeferencing and snow detection. Firstly, georeference provided the photo with spatial 


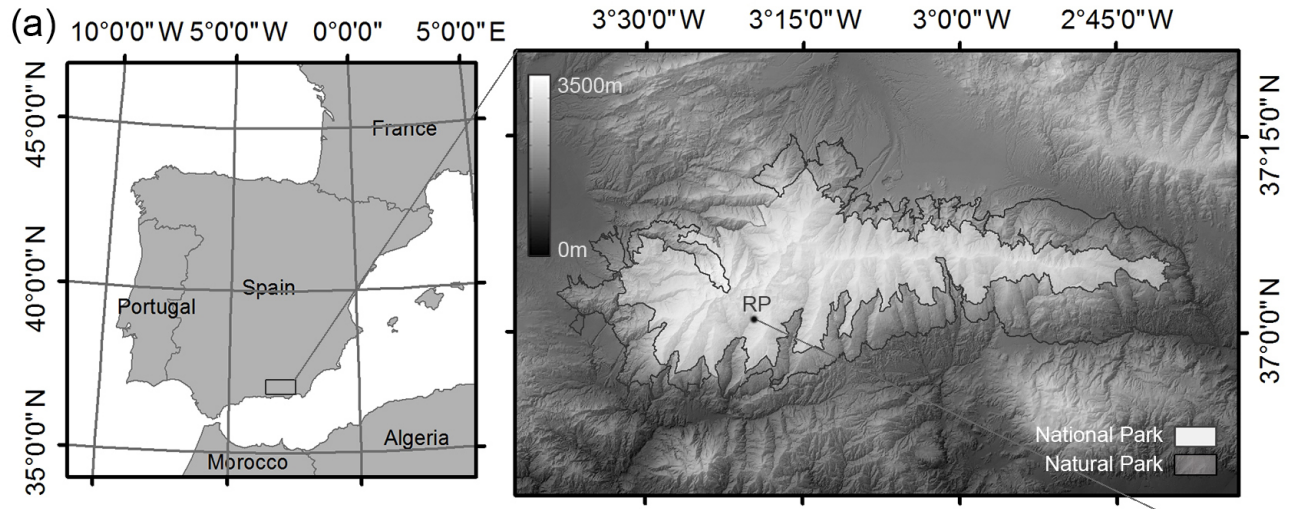

(b)

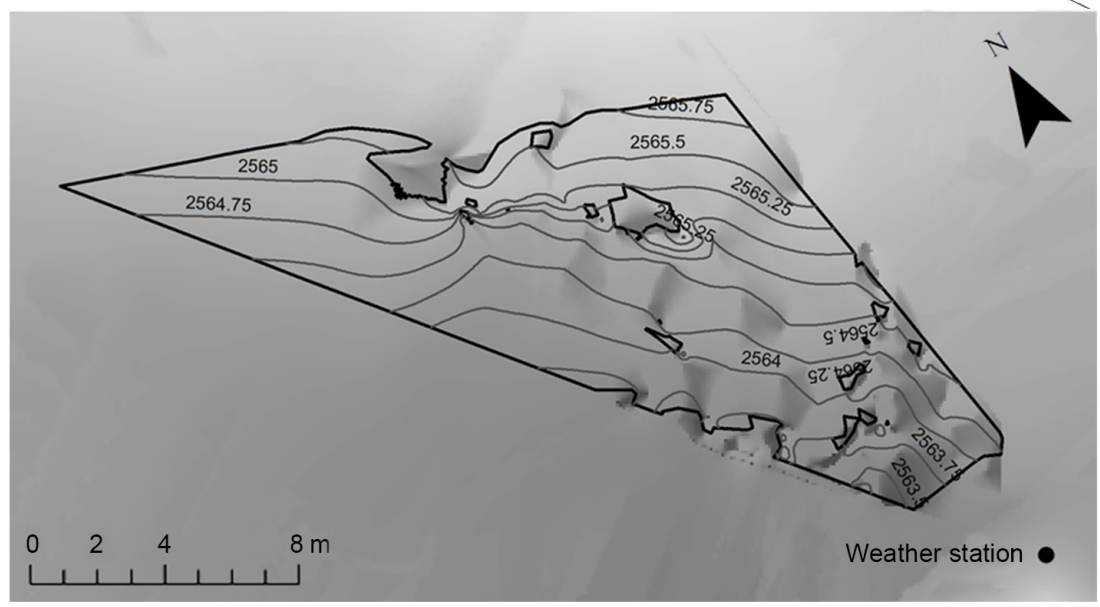

Figure 1. Location of the study site at Sierra Nevada, Spain (top), and DEM of the control area located near the Refugio Poqueira (RP) weather station (bottom). The black dot indicates the location of the weather station and the black solid line, the area covered by the images obtained from terrestrial photography.

Table 1. Statistical descriptors of selected meteorological variables at the Refugio Poqueira weather station during the study period (20092013).

\begin{tabular}{lrrr}
\hline & Mean & Max. & Min. \\
\hline Annual precipitation $(\mathrm{mm})$ & 1072 & 1460 & 537 \\
Annual snowfall fraction $(\%$ of the annual precipitation) & 65 & 83 & 45 \\
Daily temperature during the year $\left({ }^{\circ} \mathrm{C}\right)$ & 6.7 & 24.7 & -15 \\
Daily temperature during the snow season $\left({ }^{\circ} \mathrm{C}\right)$ & 1.3 & 16.3 & -15 \\
Daily solar radiation $\left(\mathrm{J} \mathrm{m}^{-2}\right)$ & $20.5 \times 10^{6}$ & $35.8 \times 10^{6}$ & $0.5 \times 10^{6}$ \\
Daily wind speed $\left(\mathrm{m} \mathrm{s}^{-1}\right)$ & 3.6 & 13.5 & 0.1 \\
\hline
\end{tabular}

references in order to identify a function that related the 3-D point in the DEM to the associated 2-D pixel in the image. For this purpose, standard automatic computer vision algorithms were applied (Fiume et al., 1989; Foley et al., 1990). Secondly, the snow detection was performed with a clustering algorithm, namely, a $K$ means algorithm (MacQueen, 1967), which classified pixels into two clusters: snow covered and non-covered. Following this pixel classification, the SCF in each image was easily calculated by the sum of pixels in each cluster (Pimentel et al., 2012).
The average snow depth, $\bar{h}$, was obtained in each image using the poles installed in the plot. They were painted bright red, which made them easy to distinguish from the other elements in the photo. A three-step procedure was followed: (1) snow pole detection in the images (Fig. 2a), (2) transformation between pixel snow depth in the pole $\left(h_{\text {ref }}\right)$ (Fig. $\left.2 b\right)$, and (3) transformation between $h_{\text {ref }}-\bar{h}$ (Fig. 2c). For this, a predefined searching window was used to isolate the poles in the images. Then, the same clustering algorithm was applied to determine pole and no-pole pixels. Only data from one 
Table 2. Statistical descriptors of the SCF and $\bar{h}$ datasets measured by using TP in the control area (Pimentel et al., 2015) for each year and during the whole study period (2009-2013).

\begin{tabular}{|c|c|c|c|c|c|}
\hline & 2009-2010 & 2010-2011 & 2011-2012 & 2012-2013 & Study period \\
\hline mean $\operatorname{SCF}\left(\mathrm{m}^{2} \mathrm{~m}^{-2}\right)$ & 0.8 & 0.88 & 0.5 & 0.75 & 0.75 \\
\hline maximum SCF $\left(\mathrm{m}^{2} \mathrm{~m}^{-2}\right)$ & 1 & 1 & 1 & 1 & 1 \\
\hline mean $\bar{h}(\mathrm{~m})$ & 0.30 & 0.56 & 0.12 & 0.31 & 0.1 \\
\hline $\operatorname{maximum} \bar{h}(\mathrm{~m})$ & 1.04 & 1.19 & 0.41 & 0.88 & 1.19 \\
\hline number of accumulation-melting cycles & 24 & 17 & 12 & 18 & 71 \\
\hline annual number of days with snow accumulation (days) & 62 & 55 & 29 & 50 & 196 \\
\hline annual number of days with snow melting (days) & 119 & 127 & 87 & 99 & 432 \\
\hline
\end{tabular}
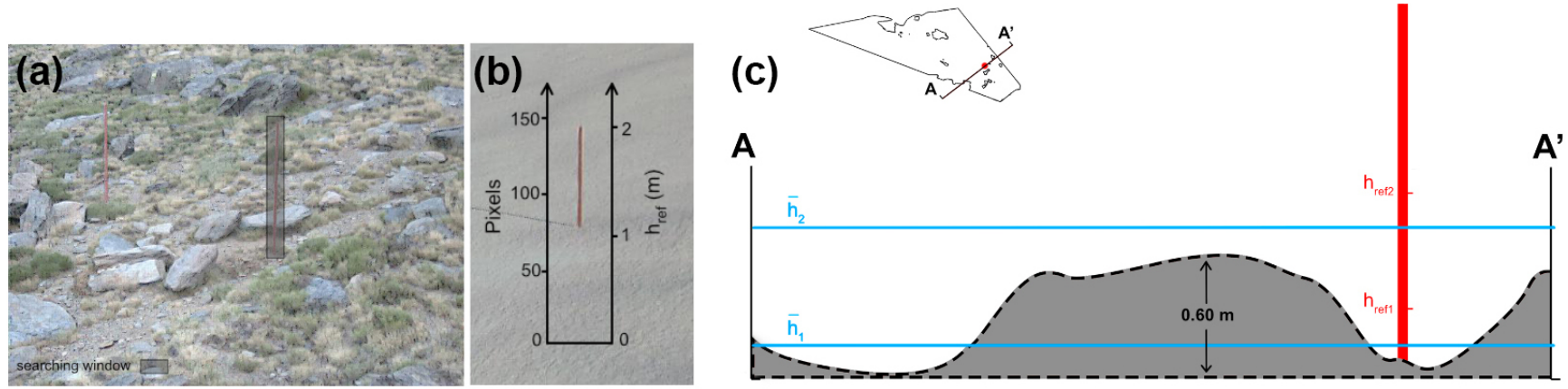

Figure 2. (a) Pole detection in the original image using a predefined searching window; (b) transformation between pixel snow depth in the pole $\left(h_{\text {ref }}\right)$; (c) a simplified 2-D representation of the relationship between $h_{\text {ref }}$ and $\bar{h}$ in each TP image of the control area.

pole were used in the study. The second one was a control test for the horizontality hypothesis adopted in the calculation of $\bar{h}$. A linear equation was applied to the thus-identified pole pixels to transform them into ( $h_{\text {ref }}$ ) (Fig. 2a). The associated $\bar{h}$ value for the whole control area was estimated for each image by assuming a horizontal surface of the snowpack accumulation distribution (Luce et al., 1999). An empirical relationship (Eq. 2) between the $h_{\text {ref }}$ value in the pole and the value of $\bar{h}$ was derived from this hypothesis, by using the exact location of the pole and the topography in the control area (Fig. 2b). A piecewise function, composed of a cubic expression for a reference snow depth below the influence height of the micro-topography, $0.6 \mathrm{~m}$ (calculated as the 99th percentile of the micro-topography distribution in the control area), and a linear relationship for reference snowdepth values higher than this threshold were obtained, where both $\bar{h}$ and $h_{\text {ref }}$ are expressed in metres, in Eq. (2).

$\bar{h}=\left\{\begin{array}{cc}-0.2764 \cdot h_{\mathrm{ref}}^{3}+0.8066 \cdot h_{\mathrm{ref}}^{2}+0.2608 \cdot h_{\mathrm{ref}} & \text { if } h_{\mathrm{ref}} \leq 0.6 \mathrm{~m} \\ h_{\mathrm{ref}}-0.2129 & \text { if } h_{\mathrm{ref}}>0.6 \mathrm{~m}\end{array}\right.$

\subsection{Snow modelling}

\subsubsection{Point model}

The snowmelt-accumulation model for a Mediterranean site, developed by Herrero et al. (2009) is a point physical model based on a mass and energy balance. The model assumes a uniform horizontal snow-cover surface distributed in one vertical layer. This snow column per unit area defines the control volume, which has the atmosphere as an upper boundary and the ground as the lower one. The lateral mass and energy fluxes between adjacent snow columns are regarded as null. The energy and mass balances are given by Eqs. (3)-(4):

$$
\begin{aligned}
& \frac{\mathrm{dSWE}}{\mathrm{d} t}=P-E+W-M, \\
& \begin{aligned}
\frac{\mathrm{d}(\mathrm{SWE} \cdot u)}{\mathrm{d} t} & =\frac{\mathrm{d} U}{\mathrm{~d} t}=K+L+H+G+R \cdot u_{R} \\
& -E \cdot u_{E}+W \cdot u_{W}-M \cdot u_{M},
\end{aligned}
\end{aligned}
$$

where SWE is the water mass in the snow column and $u$ is the internal energy per unit of mass ( $U$ for total internal energy). In the mass balance, $P$ defines the precipitation flux, $E$ is the flux of water vapour diffusion (evaporation/condensation), $W$ represents the mass transport flux due to wind, and $M$ is the melting water flux. On the other hand, regarding the energy fluxes, $K$ is the solar or shortwave radiation, $L$ is the thermal or long-wave radiation, $H$ is the flux of sensible heat exchange with the atmosphere, $G$ is the flux of heat exchange with the soil, and $u_{R}, u_{E}, u_{W}$, and $u_{M}$ are the advective heat flux terms associated with each of the mass fluxes in Eq. (3), respectively.

In the mass-balance Eq. (3), $W$ was disregarded because of the rapid snow metamorphosis, which compacts the snow 
02 December 2011
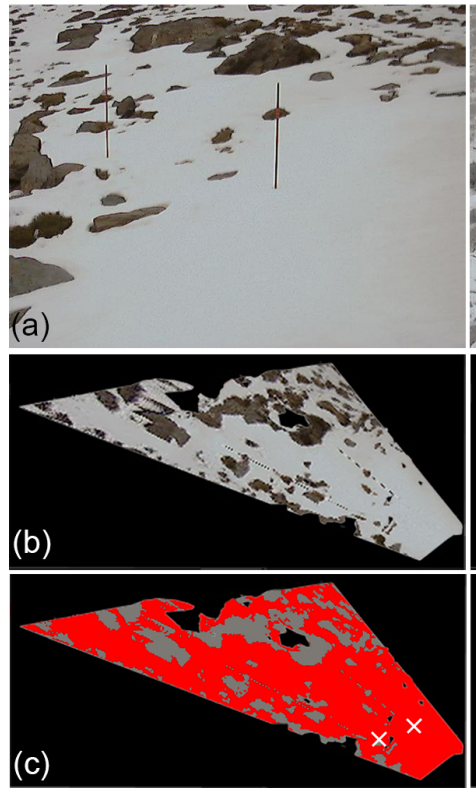

28 April 2012
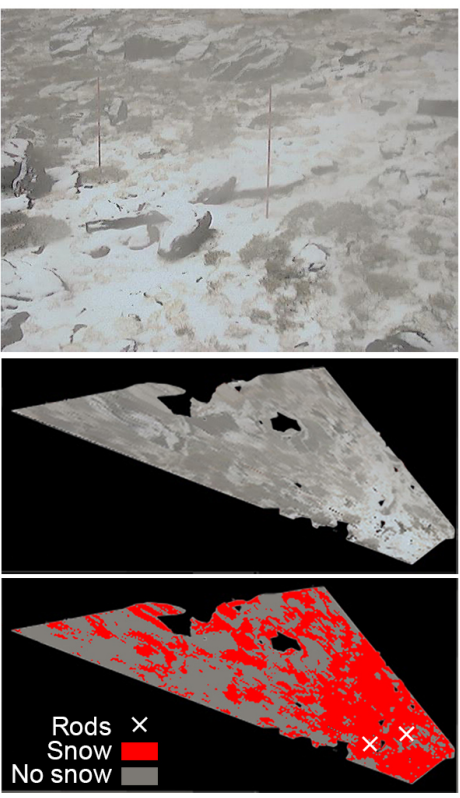

05 February 2013

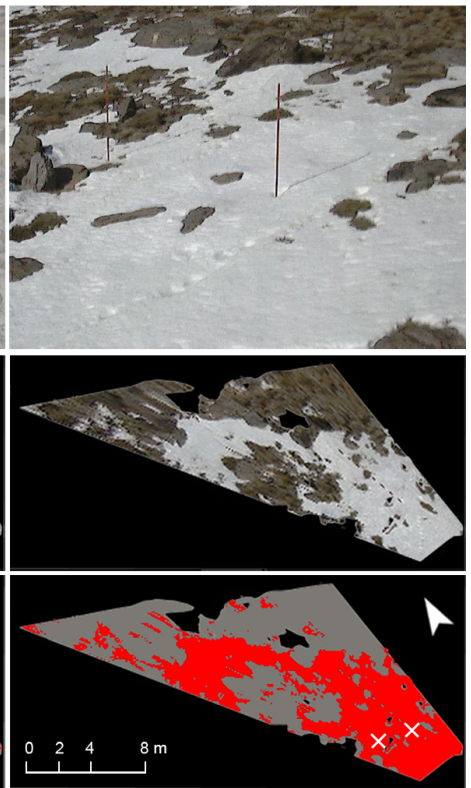

Figure 3. Selected examples of the final SCF maps $(0.05 \times 0.05 \mathrm{~m})$ obtained from the terrestrial photography treatment procedure at the study site for certain representative states during the snow season: (a) original images for each date $(30 \times 30 \mathrm{~m})$; $(\mathbf{b})$ georeferenced images; and (c) snow masks obtained from the georeferenced image by using a $K$ mean algorithm (snow presence in red). The algorithm is capable of capturing snow presence under different atmospheric conditions: cloudy, foggy, and sunny days (left to right panel in each row, respectively).

and reduces its mobility (Marks and Winstral, 2001). $G$ was not considered in the energy-balance Eq. (4) since it is regarded as a secondary term in itself in this balance (Kuusisto, 1986). The calculation of the shortwave radiation $(K)$ was based on the measured downwelling short-radiation flux and the albedo (Aguilar et al., 2010; Pimentel et al., 2016). The calculation of the long-wave radiation was based on the formulation for atmospheric long-wave emissivity, developed in the Sierra Nevada area by Herrero and Polo (2012). Finally, the $H$ term was modelled as a diffusion process (Dingman, 2002). A detailed description of the formulation of each term can be found in Herrero et al. (2009).

\subsubsection{Incorporation of accumulation-depletion curves in the point model}

The point model described in the previous section was expanded to perform calculations for a $30 \times 30 \mathrm{~m}$ cell by including the ADCs obtained from TP. In this way, SCF became a new state variable in the snow model. In time step $t_{1}$, when a snowfall event begins, the mass and energy balances are solved for the whole cell, and the snow-state variables are calculated per unit of area. SCF at this time $\left(\mathrm{SCF}_{1}\right)$ is estimated from the $\bar{h}$ calculated at this time $\left(\bar{h}_{1}\right)$ and by using the associated ADC. In the next time step $\left(t_{2}\right), \mathrm{SCF}_{1}$ is used as a reduction factor of the area affected by the mass and energy balance. This iterative process is repeated in the model whenever snow is still present in the cell.
Three hydrological years were used for calibration: 20092010, a wet year; 2010-2011, a very wet year; and 20112012, a dry year. The stability correction factors for turbulent transfer $\left(\phi_{M}, \phi_{V}\right.$, and $\left.\phi_{W}\right)$ (Cline, 1997), the sensibleheat transfer coefficient in windless conditions $\left(K_{H_{0}}\right)$, and the value of snow surface roughness $\left(z_{0}\right)$ are the calibration parameters in the snow model by Herrero et al. (2009). A 4th year of data (2012-2013) was used to validate the previous results. The mean error (ME), mean-absolute error (MAE), and root-mean-squared error (RMSE) were employed in the calibration and validation process as an objective function to be minimized and tested in the validation step with SCF and $\bar{h}$ as test variables.

\section{Results}

\subsection{Terrestrial photography measurements}

Figure 3 shows some representative examples of the SCF maps obtained from the TP georeferencing and snowdetection processes. As can be observed, the detection algorithm was able to capture snow presence even under adverse atmospheric conditions such as foggy and extremely cloudy days.

The temporal evolution of $\bar{h}$ and SCF, both measured from the TP images, is represented in Fig. 4. A high variability is observed in the accumulation-melting cycles that occurred during the 4 years of the study period. The number of cycles 

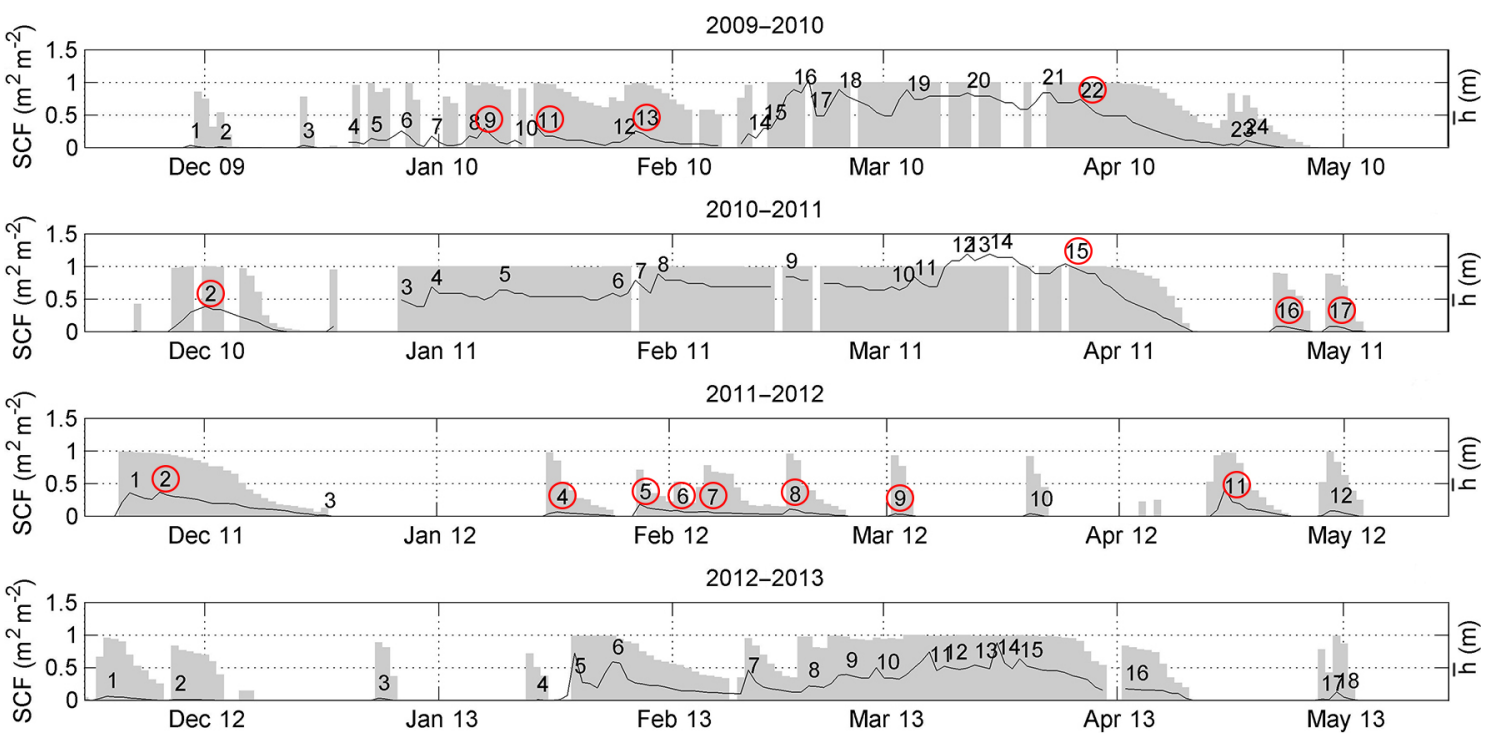

Figure 4. Temporal evolution of the daily snow-cover fraction, SCF (gray bars), and average snow depth, $\bar{h}$ (black line), obtained from TP at the control area during the 4-year study period. The accumulation-melting events are numbered for each year. Red circles indicate the events selected for the subgrid variability analysis during the 3 -year calibration period.

and their duration varied considerably during each year, with a mean number of $18 \pm 5$ cycles per year and a mean duration of $3 \pm 1$ and $6 \pm 5$ days for the accumulation and melting phases of each cycle, respectively. On an annual basis, the mean numbers of days with melting and accumulation dominance were $49 \pm 14$ and $108 \pm 18$ days, respectively. Furthermore, the mean daily snow depth fluctuated greatly from year to year, ranging from $0.12 \mathrm{~m}$ in the driest year (2011-2012) to $0.56 \mathrm{~m}$ in the wettest (2010-2011). There was a maximum average snow depth, $\bar{h}$, of $1.19 \mathrm{~m}$ in the most humid year. As for the SCF, each year the control area was completely covered for at least for 1 day, with mean daily SCF values ranging from $0.50 \mathrm{~m}^{2} \mathrm{~m}^{-2}$ to $0.88 \mathrm{~m}^{2} \mathrm{~m}^{-2}$ (Table 2).

In order to analyse subgrid variability, 16 of the $53 \mathrm{cy}$ cles during the 3 calibration years (2009-2010, 2010-2011, 2011-2012) were finally selected. Those cycles that either had a short duration of less than 5 days, or took place when the study area was completely covered by snow, were not considered in the study since they did not provide a significant amount of information. The events finally selected are those marked with a red circle in Fig. 4.

\subsection{The formulation of depletion curve and snow processes}

The ADC given by Eq. (1) was fitted to each of the cycles in Fig. 4, as explained in Sect. 3. Since the duration of the accumulation phase showed a low deviation when compared to that of the melting phase in each cycle, the data of this phase were jointly considered in the procedure. In contrast, the melting phases were individually treated for each event. Table 3 shows the fitted values of the parameters as- sociated with the melting phase of each event. As explained in Sect. 3.1, these individually fitted parameters during the melting phase were used to cluster the melting phases and identify common patterns within the cycles. The final results clustered the melting phases in four groups (identified as curves 1-4 in Table 3). The associated values of their fitted parameters are shown in Table 4, together with those corresponding to the accumulation phase (Curve 0 ).

Regarding the five ADCs given by the values in Table 4, their shape can be associated with the description of the evolution of the snowpack within the control area (Fig. 5). More specifically, Curve 0, which describes the accumulation phase of the selected cycles, produces a very fast initial accumulation that covers almost half of the maximum snow area during the accumulation phase. This rapid accumulation is followed by a somewhat slower increase, which finishes with a dimensionless snow-depth value of 0.7 , a maximum threshold beyond which the area is completely covered. As for the melting phases, Curve 1 is representative of cycles with a large amount of snow (a high $\bar{h}^{*}$ value) resulting from a long accumulation phase, and it is associated with a very compact state of the snow with a high level of metamorphism.

Curve 2 also represents melting phases with a large quantity of snow, with high initial values of snow depth. In this case, they are preceded by a short, non-persistent accumulation phase. Moreover, since melting occurs directly after the accumulation process ends, this snow is only slightly compacted. Finally, both Curve 3 and 4 represent snowmelt cycles with significantly lower snow-depth values. In these cases, the micro-topography is very likely the direct and main driver of the melting process from the beginning of 
(a)
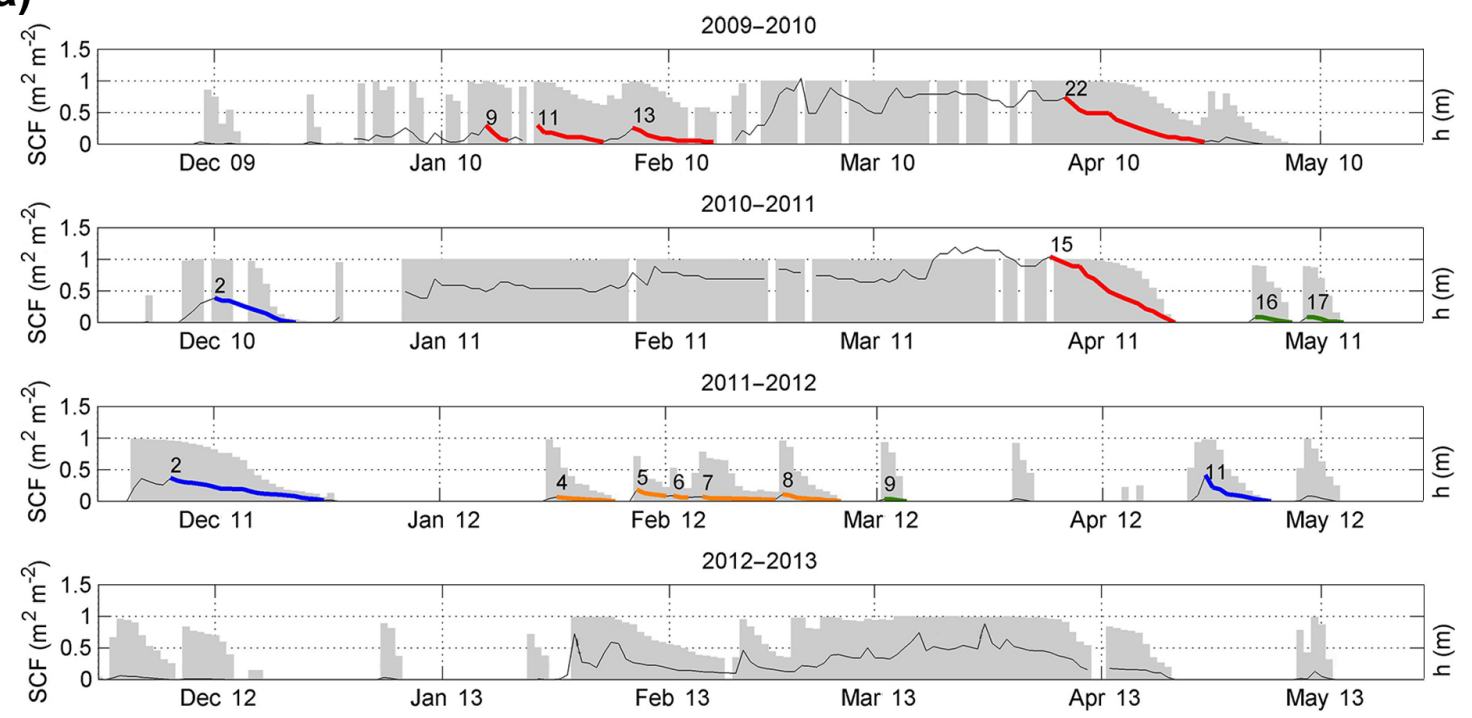

(b)
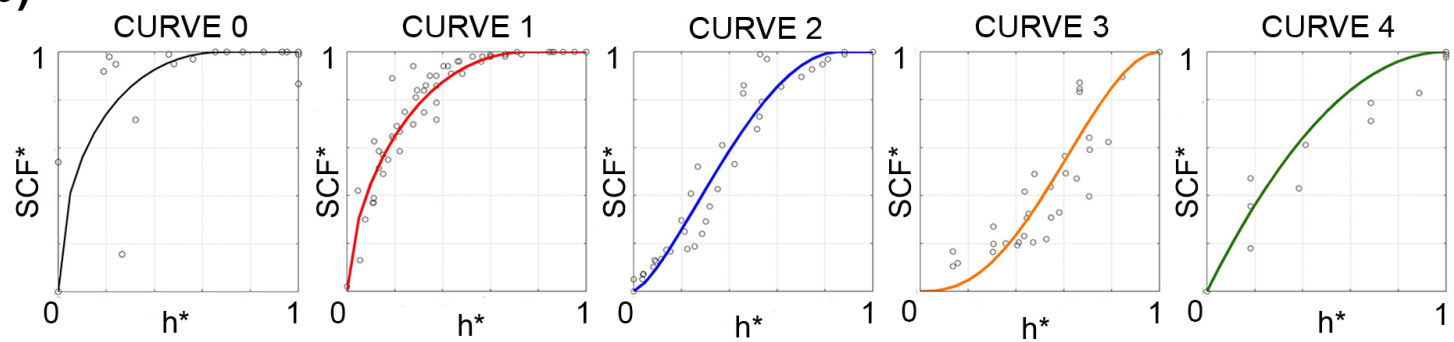

Figure 5. (a) Accumulation-melting cycles used in the study. These include selected cycles during each year of the calibration period (2009-2012) with their classification in the depletion curves (DCs) in Table 5. (b) Also included are the following ADC patterns: Curve 0, accumulation phase for all the cycles; Curve 1, melting phase of cycles with initial high snow depth, following a long accumulation stage; Curve 2, melting phase of cycles with initial high snow depth, following a short accumulation stage; Curve 3, melting phase of cycles with low snow depth at the beginning of the annual snow season (autumn-winter); and Curve 4, melting phase of cycles with low snow depth at the end of the annual snow season (spring).

this phase. In fact, the length of the snow season is the main difference between both curves: the autumn-winter cycle (Curve 3) in comparison to the spring cycle (Curve 4). In the cold months, the snowmelt rate has a fast initial value followed by a slowdown in its final stage. In contrast, in the warmer spring months, the snow decay is faster and approximately constant throughout the melting phase.

This difference in dynamics is described by the fitted parameter values in the associated DCs (Table 4). More specifically, $\bar{h}_{e}^{*}$ defines the beginning of the melting phase in each cycle. It is lower in Curve 1 than in Curve 2 (0.759 vs. 0.861) and reflects the effect of snow consolidation, which delays the beginning of the melting phase. Furthermore, its value is 1 in Curves 3 and 4, as it corresponds to cycles in which the melting phase immediately occurs after the accumulation maximum. Regarding $\bar{h}_{m}^{*}$, which determines the moment with maximum melting rates, it drops to zero in Curves 1 and 4, which are associated with quasi-stationary melting rates during this phase. In contrast, melting phases represented by Curve $2\left(\bar{h}_{m}^{*}=0.264\right)$ and Curve $3\left(\bar{h}_{m}^{*}=0.617\right)$ exhibit two different rates: a fast value and a slow value, associated with the initial and final melting stages, respectively.

Based on the previous data, a decision tree was defined to incorporate the corresponding ADC given by the fitted parameters in Table 4 into the snowmelt-accumulation point model. Figure 6 shows this decision tree, which answers this sequence of questions: (0) type of curve, accumulation or depletion; (1) the duration of the snow (number of days greater or lesser than 30) in the control area when the melting phase begins to discriminate the effects on the compaction of the snowpack; (2) the maximum snow depth during a given cycle (a threshold value of $0.60 \mathrm{~m}$ was identified as representative of the topography of the control area); and (3) the month when the cycle occurs to discriminate between autumn-winter and spring. The conditions formulated in each diamond translate these previous snow-state-related 
Table 3. Fitted values of the parameters in Eq. (1) $\left(h_{e}^{*}\right.$ and $\left.h_{m}^{*}\right)$ and the associated determination coefficient $\left(R^{2}\right)$ for the melting phase of each selected cycle during the calibration period. The last column to the right shows the groups in which each DC was finally clustered (identified as Curves 1 to 4 ).

\begin{tabular}{lrrrrrl}
\hline Year & Cycle & $\begin{array}{r}\text { Number of } \\
\text { days of } \\
\text { the cycle }\end{array}$ & $h_{e}^{*}$ & $h_{m}^{*}$ & $R^{2}$ & Type \\
\hline $2009-2010$ & 9 & 4 & 0.80 & 0.14 & 0.85 & Curve 1 \\
$2009-2010$ & 11 & 10 & 0.75 & 0.15 & 0.90 & Curve 1 \\
$2009-2010$ & 13 & 12 & 0.85 & 0.10 & 0.88 & Curve 1 \\
$2009-2010$ & 22 & 20 & 0.78 & 0.13 & 0.94 & Curve 1 \\
$2010-2011$ & 2 & 12 & 0.80 & 0.40 & 0.97 & Curve 2 \\
$2010-2011$ & 15 & 18 & 0.76 & 0.16 & 0.97 & Curve 1 \\
$2010-2011$ & 16 & 6 & 1.10 & 0.05 & 0.97 & Curve 4 \\
$2010-2011$ & 17 & 6 & 1.15 & 0.13 & 0.90 & Curve 4 \\
$2011-2012$ & 2 & 22 & 0.91 & 0.56 & 0.97 & Curve 2 \\
$2011-2012$ & 4 & 9 & 0.99 & 0.77 & 0.93 & Curve 3 \\
$2011-2012$ & 5 & 5 & 1.00 & 0.76 & 0.97 & Curve 3 \\
$2011-2012$ & 6 & 3 & 1.00 & 0.65 & 0.97 & Curve 3 \\
$2011-2012$ & 7 & 11 & 1.05 & 0.80 & 0.89 & Curve 3 \\
$2011-2012$ & 8 & 9 & 1.00 & 0.65 & 0.96 & Curve 3 \\
$2011-2012$ & 9 & 4 & 1.01 & 0.45 & 0.95 & Curve 4 \\
$2011-2012$ & 11 & 10 & 0.85 & 0.38 & 0.97 & Curve 2 \\
\hline
\end{tabular}

Table 4. Fitted values of the parameters in Eq. (1) $\left(h_{e}^{*}\right.$ and $\left.h_{m}^{*}\right)$ and the associated determination coefficient $\left(R^{2}\right)$ for both the accumulation pattern (Curve 0 ) and melting phase patterns (Curves 1 to 4 ) identified within the selected cycles during the calibration period.

\begin{tabular}{lccc}
\hline Curve & $h_{e}^{*}$ & $h_{m}^{*}$ & $R^{2}$ \\
\hline Curve 0 & 0.707 & 0.000 & 0.85 \\
Curve 1 & 0.759 & 0.000 & 0.91 \\
Curve 2 & 0.861 & 0.264 & 0.94 \\
Curve 3 & 1.000 & 0.617 & 0.85 \\
Curve 4 & 1.000 & 0.157 & 0.98 \\
\hline
\end{tabular}

conditions into test variables that the model is capable of checking out (e.g. the model does not simulate the rate of compaction but, since this process is closely related with the age of the snow, this condition has been simplified by using the number of days with continuous presence of snow). The sequence in the decision tree stems from the observations and therefore, from the importance of the process on the melting parameterized in each of them. Once the curve is selected, the use of SCF as a reduction factor is applied following the procedure explained in Sect. 3.3.2.

\subsection{Calibration and Validation}

Once the decision tree was implemented into the snow point accumulation-melting model with the ADCs given by the fitted parameter values in Eq. (1) (Table 4), different simulations were performed to optimize the performance of the model in regard to the daily $\bar{h}$ and SCF values during the cal-

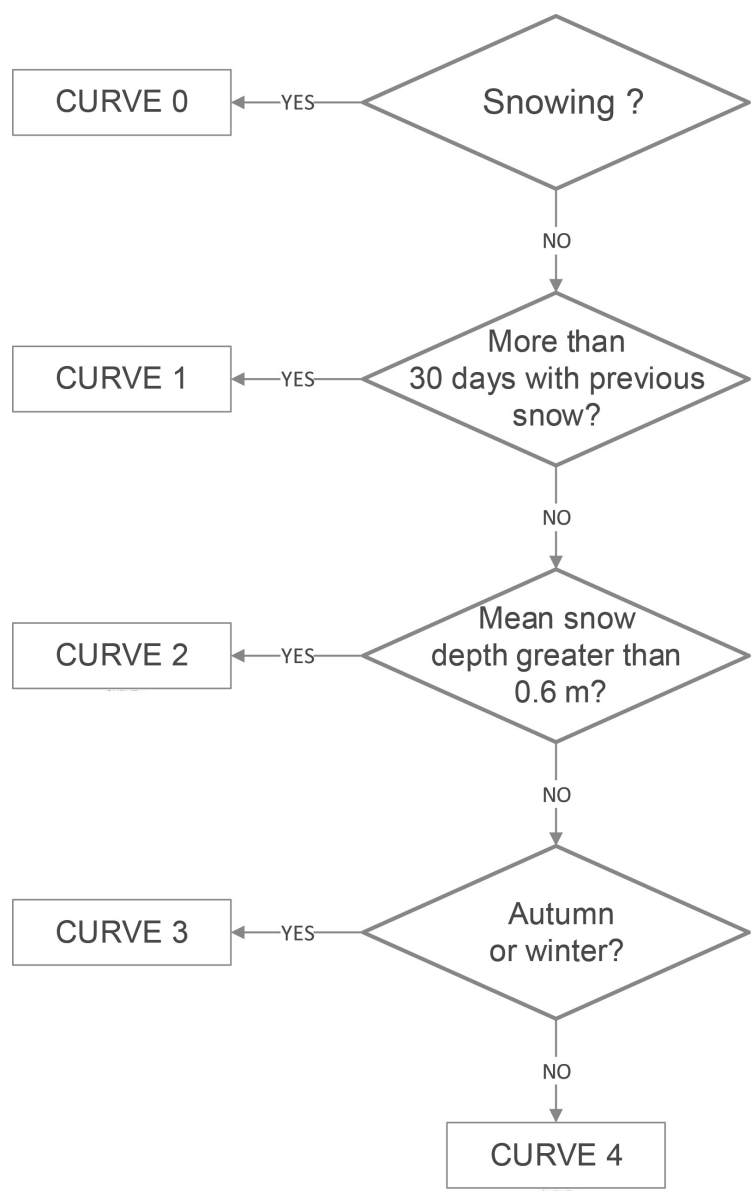

Figure 6. Decision tree included in the snow model extension for a control area of $30 \times 30 \mathrm{~m}$ to select the depletion curve associated with each accumulation-melting cycle during the snow season.

ibration period. Table 5 shows selected simulations for both variables with different calibration hypotheses, and the comparative statistics for each of the variables.

The simulations reflect the expected sensitivity of the model to the different calibration parameters. As can be observed, the use of null values of the $\phi$ factors together with high values of both $K_{H_{0}}$ and $z_{0}$ accelerate the melting stage (reflected in the positive values of ME in Simulations 1, 2 and 3 in Table 5). Furthermore, this sensitivity is more enhanced for $\bar{h}$ estimation than for SCF estimation (e.g. the reduction of the RMSE value from 214.9 to $126.7 \mathrm{~mm}$ between Simulations 1 and 3). In the same way, low values of these two parameters also delay the extinction of the snow and result in more mismatching between observed and simulated values (e.g. Simulation 5). The optimal calibration values selected for the snow model modified by ADCs were those for Simulation 7 (Table 5): (a) null values of $\phi$ factors, as proposed in other studies (e.g. Tarboton and Luce, 1996); (b) $K_{H_{0}}=1 \mathrm{Wm} m^{-2} \mathrm{~K}$, which is a value lower than what Herrero et al. (2009) found from point snow-depth mea- 
Table 5. Performance of the ADC snow model (following ADCs in Table 4) during the calibration and validation periods: calibration values used in the selected simulation trials (top) and in the validation simulations (bottom) along with the associated error indicators for both daily $\bar{h}$ and SCF in each phase. Bold values indicate the best-performance parameters in the simulation trials.

\begin{tabular}{|c|c|c|c|c|c|c|c|}
\hline \multicolumn{8}{|c|}{ Calibration (2009-2012) } \\
\hline & Simulation & $\left(\phi_{M}, \phi_{V}, \phi_{W}\right)$ & $\begin{array}{c}K_{H_{0}} \\
\left(\mathrm{~W} \mathrm{~m}^{-2} \mathrm{~K}^{-1}\right)\end{array}$ & $\begin{array}{r}z_{0} \\
(\mathrm{~mm})\end{array}$ & ME & MAE & RMSE \\
\hline \multirow[t]{8}{*}{$\bar{h}(\mathrm{~mm})$} & 1 & None & 6 & 25 & 85.1 & 93.2 & 214.855 \\
\hline & 2 & Cline & 6 & 25 & 65.0 & 74.7 & 171.2 \\
\hline & 3 & Cline & 1 & 25 & 43.1 & 57.2 & 126.7 \\
\hline & 4 & Cline & 1 & 5 & -19.4 & 50.4 & 98.1 \\
\hline & 5 & Cline & 1 & 1 & -77.0 & 88.3 & 156.8 \\
\hline & 6 & None & 1 & 1 & -28.3 & 50.2 & 98.7 \\
\hline & 7 & None & 1 & 2.5 & -0.7 & 39.6 & 84.2 \\
\hline & 8 & None & 2 & 2.5 & 5.0 & 39.3 & 85.7 \\
\hline \multirow[t]{8}{*}{$\operatorname{SCF}\left(m^{2} m^{-2}\right)$} & 1 & None & 6 & 25 & 0.069 & 0.109 & 0.243 \\
\hline & 2 & Cline & 6 & 25 & 0.028 & 0.091 & 0.207 \\
\hline & 3 & Cline & 1 & 25 & 0.002 & 0.093 & 0.205 \\
\hline & 4 & Cline & 1 & 5 & -0.070 & 0.102 & 0.221 \\
\hline & 5 & Cline & 1 & 1 & -0.118 & 0.135 & 0.259 \\
\hline & 6 & None & 1 & 1 & -0.066 & 0.091 & 0.201 \\
\hline & 7 & None & 1 & 2.5 & -0.040 & 0.079 & 0.180 \\
\hline & 8 & None & 2 & 2.5 & -0.033 & 0.077 & 0.177 \\
\hline \multicolumn{8}{|c|}{ Validation (2012-2013) } \\
\hline & Simulation & $\left(\phi_{M}, \phi_{V}, \phi_{W}\right)$ & $\begin{array}{c}K_{H_{0}} \\
\left(\mathrm{~W} \mathrm{~m}^{-2} \mathrm{~K}^{-1}\right)\end{array}$ & $\begin{array}{r}z_{0} \\
(\mathrm{~mm})\end{array}$ & $\mathrm{ME}$ & MAE & RMSE \\
\hline $\bar{h}(\mathrm{~mm})$ & - & None & 1 & 2.5 & -5.110 & 66.841 & 105.8 \\
\hline $\operatorname{SCF}\left(\mathrm{m}^{2} \mathrm{~m}^{-2}\right)$ & - & None & 1 & 2.5 & -0.112 & 0.134 & 0.219 \\
\hline
\end{tabular}

surements at the study site, but closer to those proposed by Jordan (1991) and Jordan et al. (1999) in previous works; and (c) $z_{0}=2.5 \mathrm{~mm}$, which lies within the range of $0.0001-$ $0.01 \mathrm{~m}$, as proposed by various authors (i.e. Andreadis et al., 2009; Jordan, 1991; Marks and Dozier, 1992; Marks et al., 2008; Tarboton and Luce, 1996).

Figures 7 and 8 show the values of $\bar{h}$ and SCF, respectively, during both the calibration and validation periods, along with the values simulated with the optimal calibration parameters. The simulation of SCF (Fig. 7) resulted in a high level of overall accuracy, with $\mathrm{ME}=0.040 \mathrm{~m}^{2} \mathrm{~m}^{-2}$, MAE $=0.079 \mathrm{~m}^{2} \mathrm{~m}^{-2}$, and RMSE $=0.180 \mathrm{~m}^{2} \mathrm{~m}^{-2}$. All the snowmelt cycles are represented though the simulated values generally overestimate the dataset measured during short snowmelt cycles, i.e. at the beginning of the first year or during the winter of the 3 rd year. In contrast, the model tends to underestimate the SCF during snow-persistent periods. The simulation of the average snow depth (Fig. 8) also satisfactorily reproduced snow behaviour during the calibration period with a global RMSE $=84.2 \mathrm{~mm}$. This accuracy, however, is lower in the first year, from the beginning of the winter, in which measured and simulated values show a clear mismatch even though their trends follow the same pattern. The other
2 years in the calibration period are accurately represented, and the different snowmelt cycles are adequately reproduced. This includes both the intense rates at the beginning and the end of the annual snow season as well as the long periods with a persistence of snow.

Both Figs. 7 and 8 also include the results of the model in contrast to the observations during the 4th year of data (2012-2013) in the form of a validation period (graph b in both figures) of the parameters calibrated in Simulation 7 (Table 5). Table 5 also shows the results and the statistics of this validation for both variables $\bar{h}$ and SCF. The results generally reproduced statistics similar to those achieved for the calibration period with the same behaviour observed during calibration: a general overestimation of SCF during short cycles and a mismatch in the simulated snow-depth values for certain states.

\section{Discussion}

The five proposed ADCs are capable of explaining the accumulation-melting dynamics of snow on a grid-cell scale by using (a) a similar accumulation behaviour during the study period (accumulation curve, Curve 0) and (b) four 
(a)
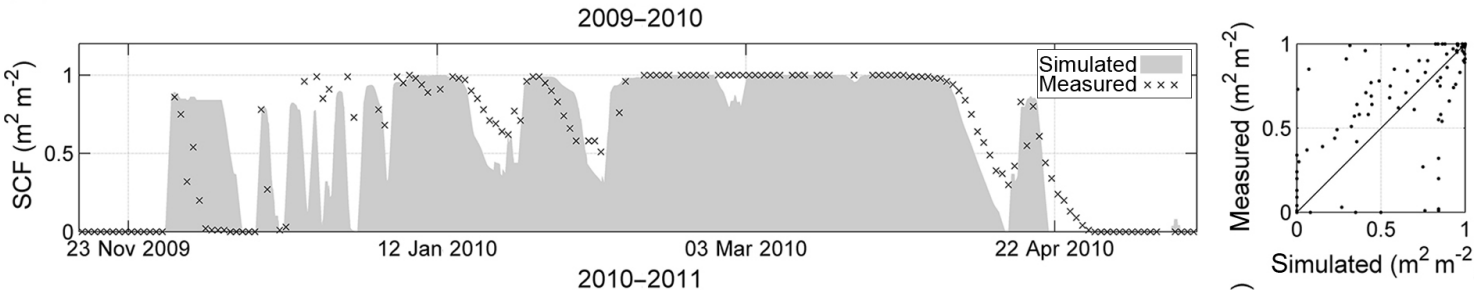

Simulated $\left(\mathrm{m}^{2} \mathrm{~m}^{-2}\right)$
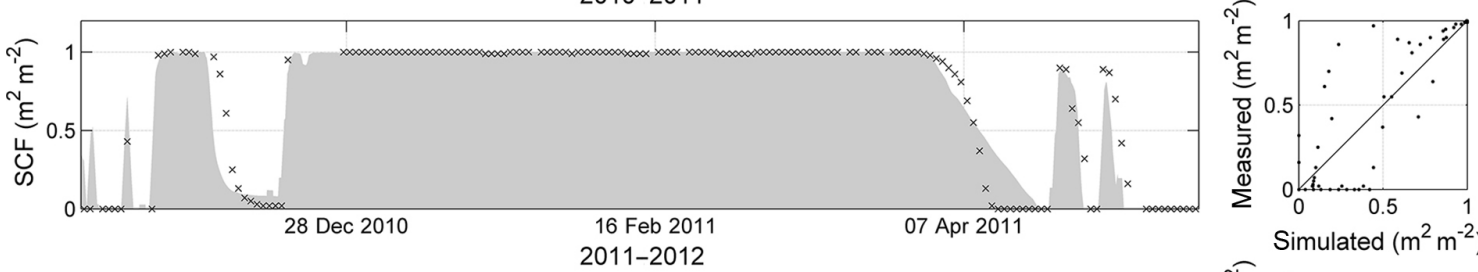

Simulated $\left(\mathrm{m}^{2} \mathrm{~m}^{-2}\right)$

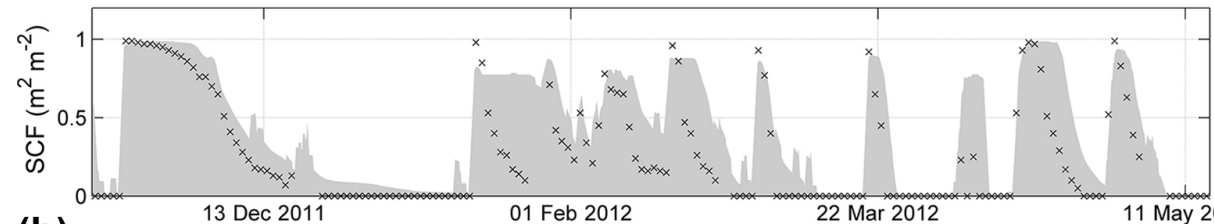

(b)

2012-2013
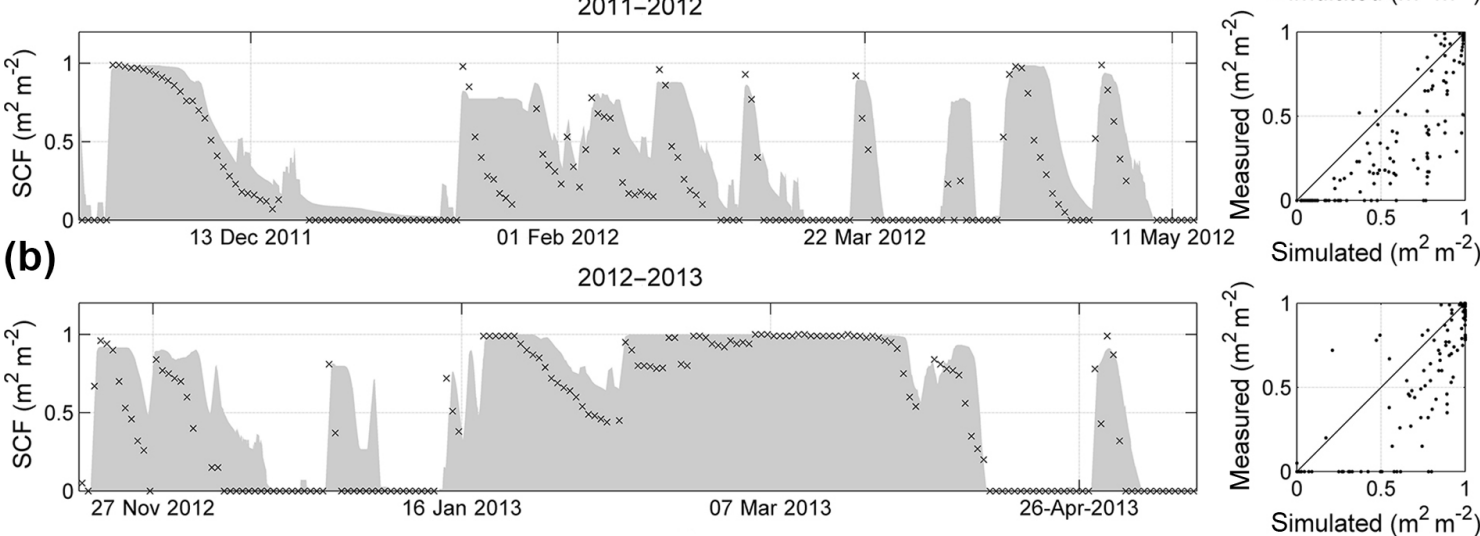

Figure 7. Temporal evolution of the measured and simulated daily SCF values, based on the calibration parameters in Simulation 7 (Table 5) during (a) the calibration period and (b) the validation period. Dispersion graphs for each year are also provided on the right.

Table 6. Importance of selected descriptors of the initial conditions and main processes associated with each depletion curve identified in this study. The number of crosses indicates the level of importance of the condition and/or process in each curve.

\begin{tabular}{|c|c|c|c|c|c|c|c|c|}
\hline & \multicolumn{2}{|c|}{ Initial conditions } & \multicolumn{3}{|c|}{$\begin{array}{c}\text { State of the snow } \\
\text { (level of compaction*) }\end{array}$} & \multicolumn{3}{|c|}{ Melting } \\
\hline & $\begin{array}{c}\text { Duration of } \\
\text { accumulation } \\
\text { stage }\end{array}$ & $\begin{array}{c}\text { Amount of } \\
\text { snow } \\
\text { depth }\end{array}$ & $\begin{array}{l}\text { Snow } \\
\text { drift }\end{array}$ & Metamorphism & $\begin{array}{l}\text { Deformation } \\
\text { strain }\end{array}$ & $\begin{array}{c}\text { Grain } \\
\text { size-Albedo }\end{array}$ & $\begin{array}{c}\text { Air } \\
\text { temperature }\end{array}$ & $\begin{array}{l}\text { Ground } \\
\text { temperature }\end{array}$ \\
\hline CURVE 1 & +++ & ++ & +++ & +++ & + & +++ & ++ & + \\
\hline CURVE 2 & ++ & ++ & +++ & ++ & + & ++ & + & + \\
\hline CURVE 3 & + & + & ++ & + & +++ & + & ++ & +++ \\
\hline CURVE 4 & + & + & + & + & +++ & + & +++ & +++ \\
\hline
\end{tabular}

* According to Armstrong and Brun (2008), the main processes that work in the compaction rate of the snow pack: (a) snow drift, (b) metamorphism, and (c) deformation strain.

melting patterns (depletion curves, Curves 1 to 4 ) depending on the initial condition of the snow at the beginning of the melting process, the state of the snow and, consequently, the main processes involved.

On the one hand, the selection of a single curve for the accumulation cycles (Curve 0) makes the model well able to simulate the accumulation phases during the study period, as can be observed in both Figs. 7 and 8, with divergences occurring mostly in the reproduction of snow-depth values after those melting events that were not fully captured by the model (that is, when the memory of the model biases the simulation). This can be also explained from the general pattern of the snowfall events in these Mediterranean regions, where heavy but quick snowfalls are very usual, with less variability than that exhibited by the melting phases. On the other hand, Table 6 sums up the main descriptors of such condi- 
(a)
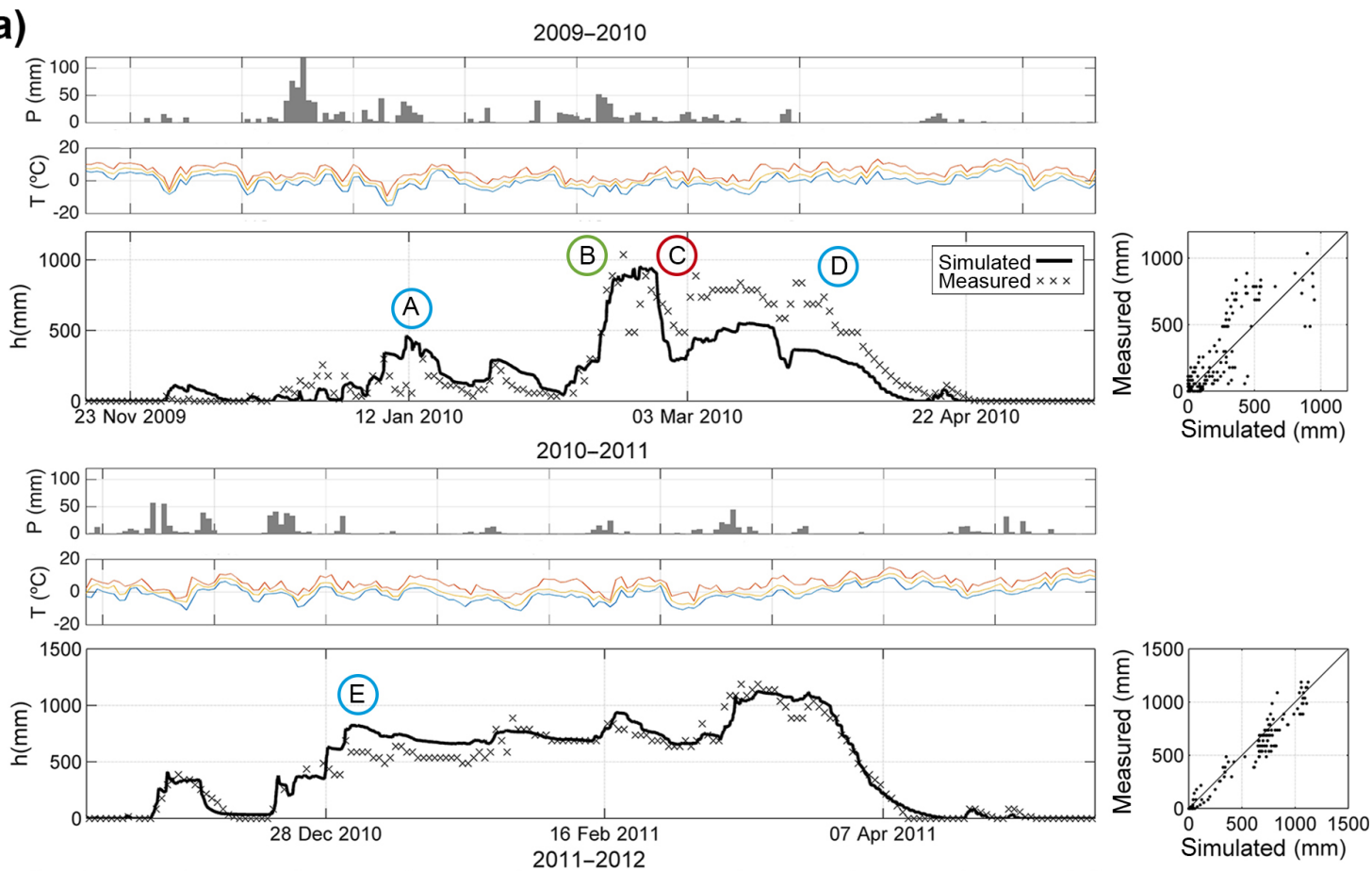

(b)
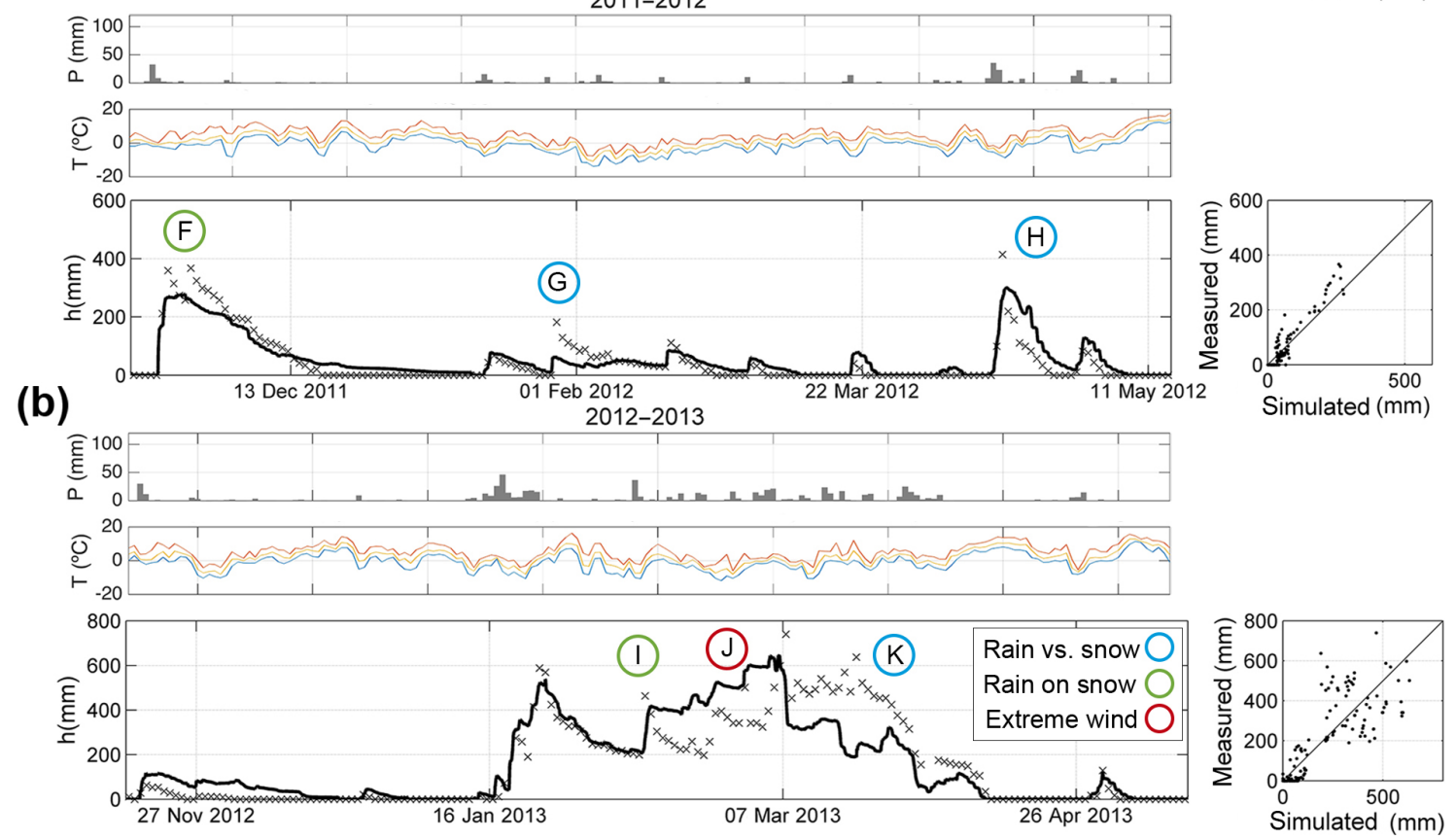

Figure 8. Temporal evolution of daily precipitation, $P$, and daily minimum (blue), mean (yellow), and maximum (red) temperature, $T$, values, together with the measured and simulated daily $\bar{h}$ values from the calibration parameters in Simulation 7 (Table 5) during (a) the calibration period and (b) the validation period. Dispersion graphs of $\bar{h}$ for each year are also provided on the right. Mismatches are identified from $\mathrm{A}$ to $\mathrm{K}$, and coloured circles are associated with the potential error sources in the modelling.

tions and processes involved in the melting process for each DC proposed. Thus, Curve 1 represents cycles with a large amount of consolidated snow, which has undergone a relatively long accumulation phase. This snow is usually highly metamorphosed due to both its long age and the exposure to a wide variety of conditions and, hence, its grain size and consequently its albedo have very likely experienced important changes. The horizontal asymptotic initial behaviour of the curve (from the point 1-1) describes this initial condition for the melting process; once the snow has retreated in a significant portion of the area, the surrounding air and ground temperature conditions the melting dynamics at the end of 
the process. Curve 2 characterizes cycles with a large amount of recent snow. The shape of the curve is similar to Curve 1; nevertheless, this snow is not much compacted and consequently the initial asymptotic behaviour is shorter. The duration of the cycle does not allow changes in the grain size larger than in the previous case. The final behaviour is very close to the previous one, with similar influence of the air and ground temperature gradients. Curve 3 has a completely different behaviour; it represents cycles with a small amount of snow during autumn or winter. It is a scarcely metamorphosed snow, where the main factors that condition its evolution are the deformation strain, very active in fresh snow after a snowfall, and the snow drift, since high wind rates are more usual during winter or autumn. In this case, with low snow-depth values, the influence of the micro-topography and ground temperature is one of the main drivers in the melting process. This is reflected in the shape of the curve, which does not have the asymptotic trend shown in the previous ones. Curve 4, cycles with a small amount of snow during spring, follows a pattern quite similar to Curve 3: a low degree of metamorphism and a high influence of deformation strain. However, snow drift is less important in spring, due to frequently lower wind-speed values during this season. For the same reason, the melting during these cycles is more influenced by the air temperature.

Furthermore, these ADCs succeeded in parameterizing the spatial distribution of the snow patches with the same type of curve. To illustrate this, Fig. 9 shows three images during each of the three cycles represented by the same curve (Curve 2). They correspond to three SCF states during the cycle $(90,50$, and $20 \%$ of the snow coverage in the control area).

A different snow distribution can be observed in images from different dates but with the same SCF value. These differences stem from the driving atmospheric conditions during the accumulation phase and the beginning of the melting stage, and their interaction with the micro-topography. For example, in the images for 2011-2012, Cycle 13, the effect that wind produced on the snow distribution can be clearly observed, with small accumulation areas close to the largest rocks.

However, all of these distributions can be accurately represented with the same curve. Hence, this parameterization captures the subgrid variability without further need to physically model the process at this scale, such as the interaction between wind and micro-topography, among others. Similar effects on the snow distribution can be observed in the sequence of states associated with the other curves.

Moreover, the dimensionless expression of the variables selected in the ADCs parameterization, $h^{*}$ and $\mathrm{SCF}^{*}$, allows for analysis of them under the light of the physical conditions prevailing during each analysed melting cycle (Table 6). The fact that the observed variability from the different patterns of the snowmelt dynamics could be associated to specific conditions, which was validated during an additional year, is an indirect support to the potential application of the DCs not only in different points in the Sierra Nevada, but also in other regions and/or similar snow-state cycles, once the order of magnitude of snow depth is locally estimated. Furthermore, these results could be used linked to remote sensing sources, such as Landsat TM data with the same cell size, or other new sources with higher spatial resolution, to calibrate and validate the distributed extension of the snow model, and the development of new data fusion algorithms, to larger areas (Molotch and Margulis, 2008).

The inclusion of this five-curve set improved the performance of the snow model obtained in previous work. The conclusions of a previous study (Pimentel et al., 2015) suggested that the use of a unique depletion curve was not enough to capture the complex dynamics of snow on this scale in these regions. Three different parameterizations of a lognormal distribution, described by their coefficient of variation $(\mathrm{CV})(\mathrm{CV}=0.4, \mathrm{CV}=0.8, \mathrm{CV}=1.2)$, were assessed following the curves proposed by Luce and Tarboton (2004). The current results show an improved performance of the snow model, with RMSE values of 84.2 and $105.8 \mathrm{~mm}$ during the calibration and validation periods, respectively, below the RMSE values of $321.3,285.4$, and $556.0 \mathrm{~mm}$ obtained in the previous work for each $\mathrm{CV}$-parameterized curve test, respectively. The performance of the multiple-DC choice in the snow model is also better than the results obtained with a single-DC choice plus the assimilation of the observed SCF values (also in Pimentel et al., 2015). Therefore, this semiempirical approximation showed itself to be powerful and, at the same time, less computationally costly than those data assimilation techniques. Moreover, this new parameterization is beyond the traditional regression trees used in snowmelt models to capture subgrid variability (Balk and Elder, 2000; Erxleben et al., 2002; Molotch et al., 2005), since it is based on a parameterization related to some physical features.

In spite of the general accuracy of these results, some mismatches occurred in certain cycles during the study period, identified as $A$ to $H$ and $I$ to $K$, respectively, for the calibration and validation periods in Fig. 8. They can be classified according to the following error sources:

1. An incorrect determination of the precipitation fraction occurring in the form of rain or snow (blue circles in Fig. 8). In this regard, the model considers precipitation as snow whenever the wet-bulb temperature is under $0{ }^{\circ} \mathrm{C}$, an assumption that generally leads to a correct representation of snowfall events. However, in certain events, this threshold overestimates the amount of snowfall, such as in cycles $\mathrm{A}$ and $\mathrm{E}$ at the beginning of winter (Fig. 8), and in all likelihood, it also underestimates this amount in the spring cycles (D, G, H, and $\mathrm{K}$ in Fig. 8).

2. The apparently insufficient representation of the effects of the rain-over-snow events (green circles in Fig. 8) by the model. 

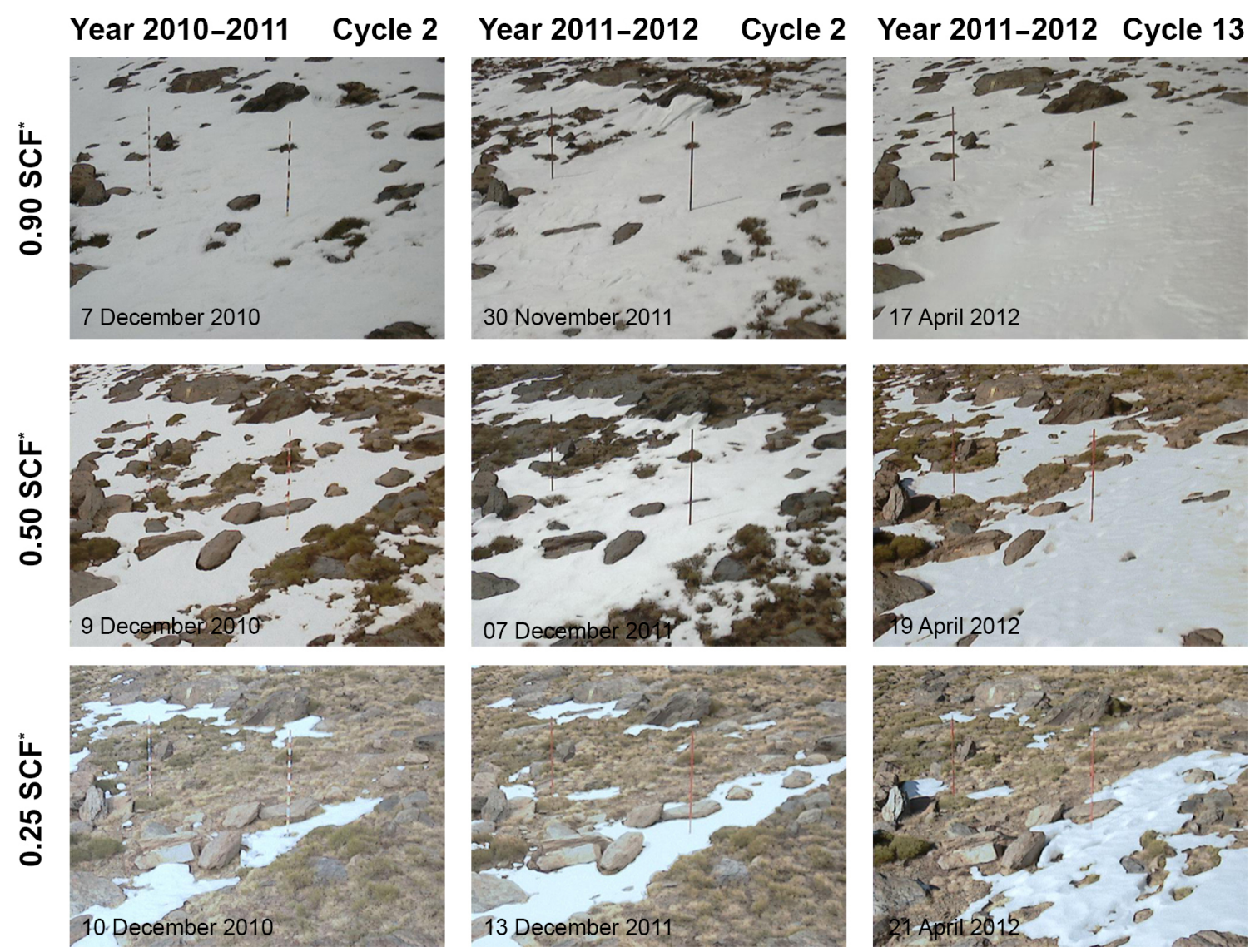

Figure 9. Selected examples of snow distribution patterns during the snowmelt phase of three different cycles represented by the same depletion curve (Curve 2).

3. The impossibility of capturing the effects of the blowing snow associated with high gusts of wind (red circles in Fig. 8). The model does not incorporate snow transport by the wind (Sect. 3.2). Despite the fact that DCs can capture this wind redistribution at the subgrid scale, at least to a certain extent, they cannot reproduce the net snow transfer from adjacent areas.

TP images facilitate the analysis of the previously mentioned error sources of error since the three factors can be identified from the original images during a given accumulation-melting cycle. This has the additional advantage of implementing this technique in snow monitoring networks, especially in highly variable conditions, such as those characterizing the climate and snow regime of Mediterranean regions.

\section{Conclusions}

This study analysed the subgrid variability of the snow distribution in a Mediterranean region and formulated a parametric approach that includes these scale effects in the physical modelling of snow by means of accumulation-depletion curves associated with snow evolution patterns. The use of terrestrial photography permitted a continuous monitoring of the snow distribution that can be easily adapted to both the spatial and temporal small-scale effects of the physical processes governing the accumulation-melting cycles. In this work, TP economically monitored the evolution of SCF and $\bar{h}$ over a $30 \times 30 \mathrm{~m}$ control area in order to study the subgrid variability of the snow, which cannot be captured by other more conventional remote sensors.

The TP information provided the data for the definition of accumulation-depletion curves corresponding to different patterns of snow accumulation-melting cycles within the annual snow season, which is a usual feature of Mediterranean environments. The five groups of ADCs succeeded in capturing the subgrid variability of different drivers at this scale, which have a direct effect on snow distribution, mainly the interaction between wind and micro-topography. The results show the importance of including different ADC patterns instead of a single one, to accurately represent snow behaviour during the different cycles within a snow season. Moreover, greater variability was found in the melting-phase patterns in the cycles than in those of the accumulation phase. All of the patterns of the accumulation phase were almost the same 
(one accumulation curve), whereas up to four patterns were found for the melting phase (four depletion curves).

These four DCs were found to be associated with the age of the snow, and the dominant atmospheric conditions during the melting. These data were used to derive a decision tree to select the appropriate DC during a given time interval, which was included in the snow model (Herrero et al., 2009) used in the study. The tree had the three following decision indicators: (i) the number of antecedent days with snow, (ii) the amount of accumulated snow previous to melting, and (iii) the month of the snow season.

The final optimal calibration of the ADC snow model improved the results previously obtained at the study site by Pimentel et al. (2015) with a single DC selected among the best of three standard curves; these results also included assimilation techniques in the modelling. The improvement of the model performance is noticeable, especially for the simulated snow-depth values, with a global error of less than $84.2 \mathrm{~mm}$, and a similarly satisfactory representation of SCF values with an error of $0.18 \mathrm{~m}^{2} \mathrm{~m}^{-2}$.

Despite this improvement, the performance of the ADCssnow model was not always satisfactory since certain cycles were not explained by the modelling. However, the information provided by the TP images permitted the analysis of potential error sources as well as the identification of additional drivers of the subgrid-scale effects, such as the occasionally incorrect determination by the model of the precipitation fraction in the form of rain or snow, the net transport of snow from adjacent areas by strong gusts of wind and rain, and a poor representation of the rain-over-snow effects. Further work is currently being carried out to improve the representation of these modelling conditions. TP is a valuable data source that complements standard weather observations (i.e. overestimation of rain and/or snow measurements) and contributes toward a better understanding of the snow behaviour under certain drivers (i.e. wind advection).

The results confirm that the use of ADCs on a cell scale, as proposed in this work, provides a solid foundation for the extension of point snow models to larger areas by means of a gridded distributed calculation. Despite the ADCs having been obtained from local observations in a small control area, the treatment of the data allows their application beyond this local scale, and the association of each curve to identified conditions and/or drivers governing the dominant processes during the snowmelt phase constitute an indirect but powerful validation of their applicability in different areas. Moreover, the $30 \times 30 \mathrm{~m}$ cell size of the control area provides a direct link to establish fusion algorithms between ground and remote sensing sources such as Landsat TM satellite and/or other recent sensors with higher spatial resolution. This constitutes the basis for current work towards the distributed extension of the ADC snow model over large areas in heterogeneous regions.

\section{Data availability}

Supplementary data are available at doi:10.1594/PANGAEA.871706 or can be provided upon request to the corresponding author.

Competing interests. The authors declare that they have no conflict of interest.

Acknowledgements. This work was funded by the Spanish Ministry of Economy and Competitiveness - MINECO (Research Project CGL 2011-25632, "Snow dynamics in Mediterranean regions and its modelling at different scales. Implication for water management" and Research Project CGL2014-58508R, "Global monitoring system for snow areas in Mediterranean regions: trends analysis and implications for water resource management in Sierra Nevada"). Moreover, this research was partially developed within the framework of the Panta Rhei Research Initiative of the International Association of Hydrological Science (IAHS) in the Working Group on Water and Energy Fluxes in a Changing Environment.

Edited by: G. Blöschl

Reviewed by: J. Parajka and two anonymous referees

\section{References}

Aguilar, C., Herrero, J., and Polo, M. J.: Topographic effects on solar radiation distribution in mountainous watersheds and their influence on reference evapotranspiration estimates at watershed scale, Hydrol. Earth Syst. Sci., 14, 2479-2494, doi:10.5194/hess14-2479-2010, 2010.

Anderson, E. A.: A point energy and mass balance model of snow cover, National Weather Service, NOAA Technical Report NWS, 19, 1976.

Anderton, S. P., White, S. M., and Alvera, B: Evaluation of spatial variability in snow water equivalent for a high mountain catchment, Hydrol. Process., 18, 435-453, 2004.

Andreadis, K. M., Storck, P., and Lettenmainer, D. P.: Modeling snow accumulation and ablation processes in forested environments, Water Resour. Res., 45, 1275-1285, 2009.

Armstrong R. L. and Brun, E.: Snow and climate: Physical Processes, Surface Energy Exchanges and Modelling, Cambridge University Press, 2008.

Balk, B. and Elder, K.: Combining binary decision tree and geostatistical methods to estimate snow distribution in a mountain watershed, Water Resour. Res., 36, 13-26, 2000.

Blöschl, G.: Scaling issues in snow hydrology, Hydrol. Process., 13, 2149-2175, 1999.

Buttle, J. M. and McDonnell, J.: Modeling the areal depletion of snowcover in a forested catchment, J. Hydrol., 90, 43-60, 1987.

Cline, D. W.: Snow surface energy exchanges and snowmelt at a continental midlatitude Alpine site, Water Resour. Res., 33, 689$701,1997$.

Corripio, J. G.: Snow surface albedo estimation using terrestrial photography, Int. J. Remote Sens., 25, 5705-5729, 2004. 
Dingman, L.: Physical Hydrology, Prentice Hall, USA, 2002.

Erxleben, J., Elder, K., and Davis, R.: Comparison of spatial interpolation methods for estimating snow distribution in the Colorado Rocky Mountains, Hydrol. Processes, 16, 3627-3649, 2002.

Farinotti., D., Magnusson, J., Huss, M., and Bauder, A.: Snow accumulation distribution inferred from time-lapse photography and simple modelling, Hydrol. Process., 24, 2087-2097, 2010.

Ferguson, R. J.: Magnitude and modeling of snowmelt runoff in the Cairngorm mountains, Scotland, Hydrolog. Sci. J., 29, 49-62, 1984.

Fiume, L.: The mathematical structure of raster graphics, Academic Press Professional, UK, 1989.

Foley, J. D., van Dam, A., Feimer, S. K., and Hughes, J. F.: Computer graphics, principles and practice, Addison-Wesley, USA, 1990.

Herrero, J. and Polo, M. J.: Parameterization of atmospheric longwave emissivity in a mountainous site for all sky conditions, Hydrol. Earth Syst. Sci., 16, 3139-3147, doi:10.5194/hess-16-31392012, 2012.

Herrero, J., Polo, M. J., Moñino, A., and Losada, M. A.: An energy balance snowmelt model in a Mediterranean site, J. Hydrol., 371, 98-107, 2009.

Jordan, R.: A one-dimensional temperature model for a snow cover, US Army Corps of Engineers, Cold Region Research \& Engineers Laboratory. Technical documentation for SNTERERM.89, Special Report 91-16, 1991.

Jordan, R. E., Andreas, E. L., and Makshtas, A. P.: Heat budget of snow-covered sea ice at North Pole 4, J. Geophys. Res., 104, 7785-7806, 1999.

Kolberg, S. A. and Gottschalk, L.: Updating of snow depletion curve with remote sensing data, Hydrol. Process., 20, 23632380, 2006.

Kuusisto, E.: The energy balance of a melting snow cover in different environments, Proceeding Modeling Snowmelt-Induced Processes, Budapest, IAHS, 155, 1986.

Luce, C. H. and Tarboton, D. G.: The application of depletion curves for parameterization of subgrid variability of snow, Hydrol. Process., 18, 1409-1422, 2004.

Luce, C. H., Tarboton, D. G., and Cooley, K. R.: Subgrid parameterization of snow distribution for an energy and mass balance snow cover model, Hydrol. Process., 13, 1921-1933, 1999.

MacQueen, J. B.: Some methods for classification and analysis of multivariate observations, Proceeding, Fifth Symposium on Math, Statistics, and Probability, Berkeley, CA, 281-297, 1967.

Marks, D. and Dozier, J.: Climate and energy exchange at the snow surface in the alpine region of Sierra Nevada. 2 Snow cover energy balance, Water Resour. Res., 28, 3043-3054, 1992.

Marks, D. and Winstral, A.: Comparison of snow deposition, the snow cover energy balance, and snowmelt at two sites in a semiarid mountain basin, J. Hydrometeorol., 2, 213-227, 2001.

Marks, D., Winstral, A., Flerchinger, G., Reba, M., Pomeroy, L., Link, T., and Elder, K.: Comparing simulated and measured sensible and latent heat fluxes over snow under a pine canopy to improve an energy balance snowmelt model, J. Hydrometeor., 9, 1506-1522, 2008.
Molotch, N. P. and Margulis, S. A.: Estimating the distribution of snow water equivalent using remotely sensed snow cover data and a spatially distributed snowmelt model: A multi-resolution, multi-sensor comparison, Ad. Water Resour., 31, 1503-1514, 2008.

Molotch, N. P., Colee, M. T., Bales, R. C., and Dozier, J.: Estimating the spatial distribution of snow water equivalent in an alpine basin using binary regression tree models: The impact of digital elevation data and independent variable selection, Hydrol. Process., 19, 1459-1479, 2005.

Pérez-Palazón, M. J., Pimentel, R., Herrero, J., and Polo, M. J.: Analysis of snow spatial and temporary variability through the study of terrestrial photography in the Trevelez river valley, Proc. SPIE 9239, Remote Sensing for Agriculture, Ecosystems, and Hydrology XIV, Edimburgh, 2014.

Pérez-Palazón, M. J., Pimentel, R., Herrero, J., Aguilar, C., Perales, J. M., and Polo, M. J.: Extreme values of snow-related variables in Mediterranean regions: trends and long-term forecasting in Sierra Nevada (Spain), Proc. IAHS, 369, 157-162, doi:10.5194/piahs-369-157-2015, 2015.

Pimentel, R., Herrero, J., and Polo, M. J.: Terrestrial photography as an alternative to satellite images to study snow cover evolution at hillslope scale, Proc. SPIE 8531, Remote Sensing for Agriculture, Ecosystems, and Hydrology XIV, Edinburgh, SPIE, Remote Sensing, 2012.

Pimentel, R., Herrero, J., Zeng, Y., Su, Z., and Polo, M. J.: Study snow dynamics at subgrid scale in semiarid environment combining terrestrial photography data assimilation techniques, J. Hydrometeorol., 6, 967-980, 2015.

Pimentel, R., Aguilar, C., Herrero, J., Pérez-Palazón, M. J., and Polo, M. J.: Comparison between Snow Albedo Obtained from Landsat TM, ETMC Imagery and the SPOT VEGETATION Albedo Product in a Mediterranean Mountainous Site, Hydrology, 3, 10, doi:10.3390/hydrology3010010, 2016.

Pomeroy, J. W., Gray, D. M., Brown, T., Hedstrom, N. R., Quinton, W. L., Granger, R. J., and Carey, S. K.: The cold regions hydrological model: a platform for basing process representation and model structure on physical evidence, Hydrol. Process., 21, 2650-2667, 2007.

Rivera, A., Corripio, J. G., Brock, B., Clavero, J., and Wendt, J.: Monitoring ice capped active VolcánVillarrica in Southern Chile by mean of terrestrial photography combined with automatic weather stations and GPS, J. Glaciol., 54, 920-930, 2008.

Sturm, M. and Holmgrem, J.: Effects of microtopography on texture, temperature and heat flow in Artic and sub-Artic snow, Ann. Glaciol., 19, 63-68, 1994.

Tarboton, D. G. and Luce, C. H.: Utah Energy Balance Snow Accumulation Melt Model (UEB), Computer Model Technical Description and User Guide. Utah Water Research Laboratory and USDA Forest Service Intermountain Research Station, 1996.

Wigmosta, M. S., Vail L. W., and Lettenmaier, D. P.: A distributed hydrology-vegetation model for complex terrain, Water Resour. Res., 30, 1665-1679, 1994.

Yin, X., Goudriaan, J., Lantinga, E. A., Vos, J., and Spiertz, H. J.: A flexible sigmoid function of determinate growth, Ann. Bot., 91, 361-371, 2003. 